\title{
Continuous ambulatory peritoneal dialysis after the honeymoon: review of experience in Newcastle 1979-84
}

\author{
A HEATON, R S C RODGER, L SELLARS, T H J GOODSHIP, K FLETCHER, \\ N NIKOLAKAKIS, M K WARD, R WILKINSON, D N S KERR
}

\begin{abstract}
Two hundred and twenty nine consecutive patients (129 men, mean age 45) were reviewed 12 to 65 months after starting treatment with continuous ambulatory peritoneal dialysis (CAPD) from January 1979 to December 1983. They received CAPD for a mean of 19.8 (range 0.5-62) months. Actuarial patient survival was $79 \%$ at 24 months and $72 \%$ at 36 months. Half of the 46 deaths were related to cardiovascular disease, while eight patients died of abdominal complications, including three patients with peritonitis. Peritonitis occurred at a rate of one episode per 35 patient weeks, and $88 \%$ of episodes were cleared by one or more courses of antibiotics. This still left peritonitis as the commonest cause of failure of CAPD, leading to a permanent change of treatment in $\mathbf{4 4}$ patients and temporary interruption in a further 25 .

CAPD remains a reasonable medium term treatment in chronic renal failure. Despite the persisting problem of peritonitis the results are comparable with those achieved by haemodialysis, and CAPD has become the treatment of first choice for end stage renal failure in Newcastle. In younger patients judged unsuitable for transplantation and facing long term dialysis, however, haemodialysis is preferred.
\end{abstract}

\section{Introduction}

Continuous ambulatory peritoneal dialysis (CAPD) was first described in $1976^{1}$ and soon became a practical alternative to haemodialysis in patients with chronic renal failure. ${ }^{2}$ The clinical use of CAPD has grown rapidly since 1979 but is still regarded by many as an acceptable treatment for only a few patients, including the elderly and patients with diabetes. The main disadvantage of CAPD is peritonitis, which leads to a high drop out rate, though many centres in Europe have used CAPD for only high risk patients, and some centres treat small numbers of patients under conditions that are far from ideal. The European registry of dialysis patients showed that up to $60 \%$ of patients starting CAPD transferred to another form of treatment within two years. ${ }^{34}$ The corresponding figure for haemodialysis is much lower and depends on the transplant rate. These figures do not amount to a controlled trial of CAPD $v$ conventional haemodialysis; such a trial has not been performed and probably never will be.

There are several advantages associated with CAPD. It is simple to perform and requires no expensive equipment. Patients like their independence and feeling of general well being. ${ }^{5}$ Fluid balance,

\footnotetext{
Department of Medicine, University of Newcastle upon Tyne, Royal Victoria Infirmary, Newcastle upon Tyne NE1 4LP

A HEATON, MRCP, senior registrar

R S C RODGER, MRCP, lecturer in medicine

L SELLARS, MRCP, first assistant in nephrology

T H J GOODSHIP, MRCP, senior research associate

K FLETCHER, HND, research associate

N NIKOLAKAKIS, MD, research associate

$M$ K WARD, FRCP, senior lecturer in medicine

$\mathrm{R}$ WILKINSON, $\mathrm{FRCP}$, reader in medicine

D N S KERR, FRCP, professor of medicine
}

Correspondence to: Dr A Heaton, Renal Unit, Norfolk and Norwich Hospital, Norwich. blood pressure, and bone disease are well controlled, and haemoglobin concentrations tend to be higher than in patients receiving haemodialysis. ${ }^{67}$ These reasons, coupled with limited facilities for $\frac{\bar{\sigma}}{\overline{0}}$ haemodialysis, have ensured the rapid increase in use of CAPD in Newcastle from 1979 to 1983 . We report results from Newcastle, as $\varrho$ they represent a large study of CAPD as first line treatment for patients with chronic renal failure from a single centre.

\section{Patients and methods}

Two hundred and twenty nine consecutive patients $(129$ men) aged $3 \stackrel{3}{3}$ months to 75 years (mean age 45 ) started receiving CAPD during the five years from January 1979 to December 1983 . They were followed up for 12 to $\omega$ 65 months after starting treatment, having received CAPD for 0.5 to $62 \mathrm{G}$ (mean 19.8) months. This represents 378 patient years of experience of $\mathcal{N}$ CAPD. Patients attended two hospitals-namely, the Royal Victoria 6 Infirmary and Freeman Hospital, which together comprise the Newcastle renal unit.

All patients judged suitable for dialysis were treated, and this amounted to between 31 and 39 new patients/year/million population (catchment population 1877000 ) during the study. The proportion of new patients requiring renal replacement treatment who were treated by CAPD increased steadily over the first two years and remained at $60-70 \%$ thereafter (table I). Patients

\begin{tabular}{lcc}
$\begin{array}{l}\text { TABLE } \\
\text { replacement } \\
1979-83\end{array}$ & treatment in Newcastle \\
\hline & \multicolumn{3}{c}{$\begin{array}{c}\text { No of patients starting renal } \\
\text { replacement treatment }\end{array}$} \\
\cline { 2 - 3 } Year & Total & CAPD (\%) \\
\hline 1979 & 64 & $22(34)$ \\
1980 & 74 & $29(39)$ \\
1981 & 58 & $39(67)$ \\
1982 & 66 & $43(65)$ \\
1983 & 72 & $44(61)$
\end{tabular}

with active abdominal disease or previous multiple abdominal surgery were excluded, as were patients who, because of severe physical or mental disease, $\stackrel{\Omega}{\partial}$ would not have coped with this form of dialysis, though several borderline patients were included for a trial of CAPD. Of the 229 patients, 177 received 0 CAPD as a first renal replacement treatment, 20 had renal transplants that were failing, 12 were transferred from hospital haemodialysis, 12 were $\mathbb{G}$ transferred from home haemodialysis, and eight were transferred from $D$ intermittent peritoneal dialysis. The underlying renal diseases were glomerulonephritis ( 58 patients $(25 \%)$ ), chronic pyelonephritis and obstruction $(33(14 \%))$, polycystic kidneys $(23(10 \%))$, vascular disease and hypertension (31 $(14 \%))$, diabetic nephropathy $(10(4 \%))$, uncertain $(41(18 \%))$, and other $\omega$ (33 (14\%)).

Access to the peritoneal cavity was gained with an indwelling double cuff 0 Tenckhoff peritoneal dialysis catheter, usually inserted under general $\frac{\text { }}{\mathbb{D}}$

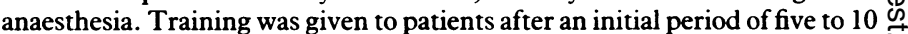
days on intermittent peritoneal dialysis to allow healing of the subcutaneous tunnel. Training as an inpatient took seven to 21 days. Patients performed 0 four (range three to five) exchanges a day, usually of 2 litres but less in $\overrightarrow{\mathbb{D}}$ children or small adults, with commercial dialysis fluid (Travenol or Fresenius) that contained sodium $132 \mathrm{mmol}(\mathrm{mEq}) / 1$, calcium $1.75 \mathrm{mmol} / 1$ ( $7 \stackrel{\mathrm{Q}}{\mathrm{Q}}$ $\mathrm{mg} / 100 \mathrm{ml})$, magnesium $0.75 \mathrm{mmol} / 1(1.8 \mathrm{mg} / 100 \mathrm{ml})$, chloride 102 우 $\mathrm{mmol}(\mathrm{mEq}) / \mathrm{l}$, lactate $35 \mathrm{mmol} / \mathrm{l}(315 \mathrm{mg} / 100 \mathrm{ml})$, and glucose in variable $ᄋ$ concentrations. All patients were encouraged to eat a diet containing at least $1.2 \mathrm{~g}$ protein $/ \mathrm{kg}$ body weight and advised on moderate restriction of potassium, phosphate, and fluid intake as appropriate. 
Hyperphosphataemia was controlled with calcium carbonate supplements (1-3 g daily) or by aluminium hydroxide capsules (Alucap, two to six daily) Overall, 169 patients $(74 \%)$ took one or both of these drugs, but the proportion taking calcium carbonate decreased and the proportion taking aluminium hydroxide increased with increasing length of treatment with CAPD. The trends coincided with an increase in serum calcium concentration in the patients and changing concerns in the doctors caring for them. Anxiety about aluminium intoxication diminished as it became apparen that serum aluminium stabilised at a moderately increased concentration,

TABLE II-Causes of death in patients treated with continuous ambulatory peritoneal dialysis and haemodialysis

\begin{tabular}{|c|c|}
\hline Cause of death & No of patients \\
\hline \multicolumn{2}{|c|}{ Continuous ambulatorv peritoneal dialysis } \\
\hline Cardiovascular: & 23 \\
\hline Myocardial infarction & 8 \\
\hline Cerebrovascular disease & 6 \\
\hline Congestive cardiac failure & 3 \\
\hline Pulmonary embolus & 2 \\
\hline Arrhythmia & 2 \\
\hline Ruptured aortic aneurysm & 1 \\
\hline Cardiac tamponade & 1 \\
\hline Abdominal: & 8 \\
\hline Peritonitis & 3 \\
\hline Pancreatitis & 1 \\
\hline Perforated duodenal ulcer & 1 \\
\hline Mesenteric infarct & 1 \\
\hline Pseudomembranous colitis & 2 \\
\hline Septicaemia (focus unknown) & 2 \\
\hline Pneumonia & 4 \\
\hline Carcinomatosis & 2 \\
\hline Treatment withdrawn & 5 \\
\hline Unknown & 2 \\
\hline Total & 46 \\
\hline \multicolumn{2}{|c|}{ Haemodialysis } \\
\hline Cardiovascular: & 25 \\
\hline Myocardial infarction & 10 \\
\hline Cerebrovascular disease & 5 \\
\hline Congestive cardiac failure & 6 \\
\hline $\begin{array}{l}\text { Arrhythmia } \\
\text {. }\end{array}$ & 2 \\
\hline Subacute bacterial endocarditis & 1 \\
\hline Ruptured aortic aneurysm & 1 \\
\hline Abdominal: & 2 \\
\hline Pelvis abscess & 1 \\
\hline Gastrointestinal haemorrhage & 1 \\
\hline Septicaemia (focus unknown) & 3 \\
\hline Pneumonia & 4 \\
\hline Carcinomatosis & 3 \\
\hline Treatment withdrawn & 6 \\
\hline Hyperkalaemia & 1 \\
\hline Unknown & 6 \\
\hline Total & 50 \\
\hline
\end{tabular}

though complacency about this has been disturbed by recent measurements of bone aluminium concentrations. At the same time concern about metastatic calcification increased. ${ }^{8}$ A quarter of all patients were receiving alfacalcidol at any one time $(0 \cdot 25-1 \mu \mathrm{g}$ daily), and there was no change in the proportion with increasing length of treatment with CAPD.

Peritonitis was diagnosed when at least two of the following symptoms were present: pain, $>50$ white blood cells $/ \mathrm{ml}$ of dialysate, and positive dialysate culture. The detailed management of peritonitis in this centre has been described previously..$^{7910}$

Patient survival and success of the technique were calculated with the actuarial method. ${ }^{11}$ The patients who started receiving CAPD from January 1979 to December 1983 were treated as a cohort and followed until December 1984; the minimum follow up therefore was 12 months. All deaths were recorded, whether the patient was still receiving CAPD, had been transferred to haemodialysis, or had received a transplant. Such deaths were attributed to CAPD no matter for how long or short a period the patient received this form of treatment. Technique success was calculated in two ways, counting a successful transplant either as technique failure or as lost to follow up. Patients were considered to have stopped CAPD if there was an interruption of at least eight weeks, and the technique was considered to have failed in these patients. Stoppages of less than eight weeks-for example, due to hernia repair-were regarded as temporary interruptions and not as failures.

Fifty patients who had been treated predominantly by haemodialysis died between January 1980 and October 1985; their causes of death were determined retrospectively from the case notes. These patients had never had CAPD, but some had had short periods of intermittent peritoneal dialysis.

\section{Results}

Survival-During follow up 46 patients died, of whom 23 had a postmortem examination. Actuarial patient survival was $79 \%$ at 24 months and $72 \%$ at 36 months (figure). The corresponding figures for survival of patients aged under 50 , were $85 \%$ and $83 \%$, respectively, and for those aged over $50,71 \%$ and $60 \%$, respectively. Cardiovascular disease accounted for half the deaths both in patients treated with CAPD and in those treated with haemodialysis (table II). Deaths from abdominal complications were relatively more common in patients treated with CAPD. Four of the 10 diabetic patients died during the observation period, two from myocardial infarction, one from stroke, and one with peripheral vascular disease from whom treatment was withdrawn. Of the 229 patients who started CAPD, 102 continued without interruption and 127 stopped at some stage. The commonest reason for stopping CAPD was peritonitis (table III). The success of the technique at 36 months was $42 \%$ overall and $53 \%$ if patients who had received a successful transplant were regarded as lost to follow up (figure).

Temporary interruption of CAPD - Fifty five patients had to be transferred on 68 occasions (table III) lasting up to two months to an alternative form of dialysis, usually haemodialysis but occasionally intermittent peritoneal dialysis. The commonest reason for interruption of treatment was again peritonitis. Twelve patients resumed CAPD after a transplant failed.
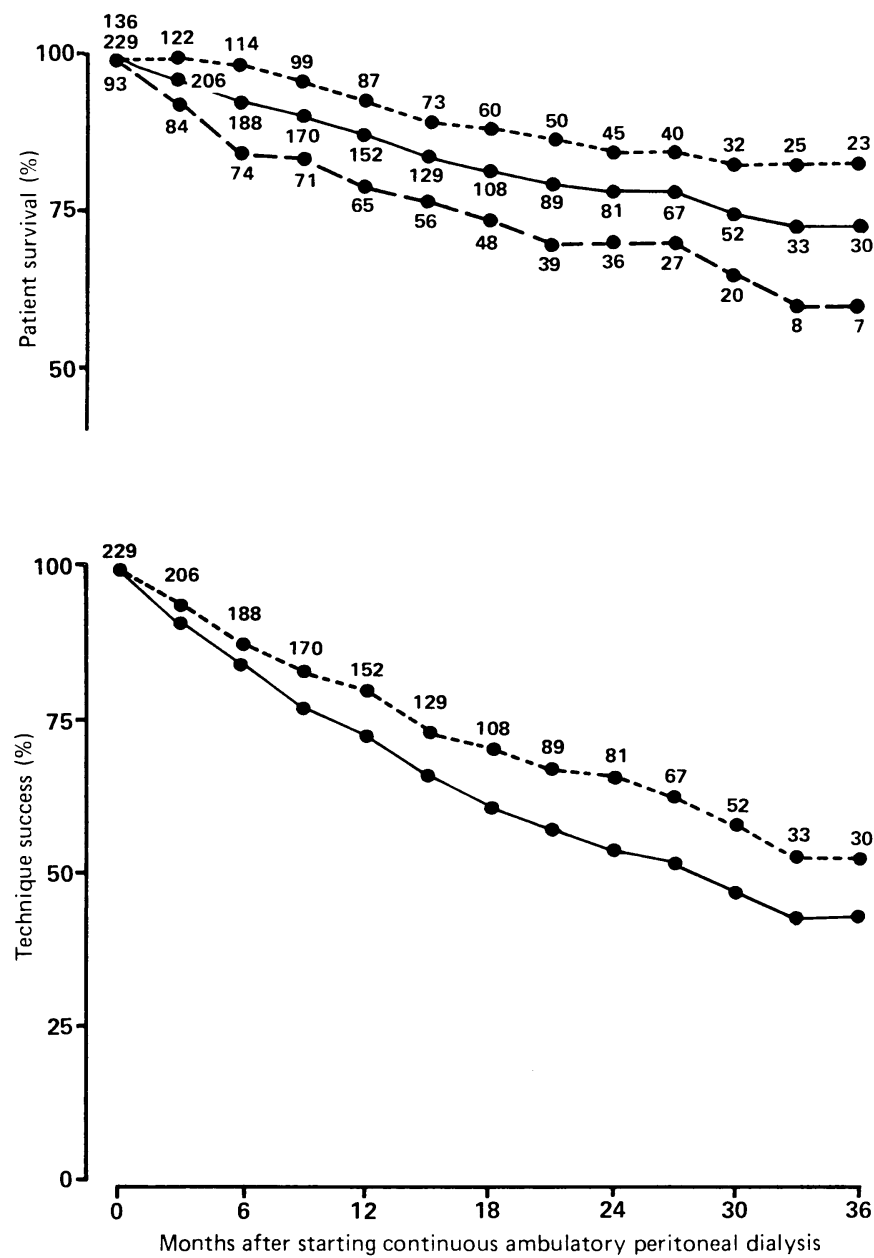

Top: Actuarial patient survival $(\%)(\bullet-\bullet)$ in 229 patients up to 36 months after start of treatment with continuous ambulatory peritoneal dialysis $(\bullet \ldots=$ survival in patients aged $\langle 50, \bullet--\bullet=$ survival in patients aged 50 and over). Figures are numbers of patients entering each time interval. Bottom: Proportion of patients (\%) still undergoing treatment with continuous ambulatory peritoneal dialysis up to 36 months after starting treatment, regarding transplant as technique failure $(\bullet \bullet)$ or as lost to follow up $(\bullet-\bullet)$. Figures are numbers of patients entering each time interval.

Cardiovascular disease-Forty eight patients had evidence of pre-existing ischaemic heart disease (angina or previous myocardial infarction) when they started CAPD. Of these, 15 (31\%) died compared with 31 (17\%) of 181 patients who did not show evidence of pre-existing ischaemic heart disease and who died during follow up. Fifteen patients, including seven of the 48 with pre-existing disease, had a myocardial infarction during follow up that 
was fatal in eight cases. Of the 30 patients who had angina before starting dialysis, the symptoms improved or disappeared in 17, remained the same in 11 , and worsened in only two during CAPD. Twelve of these patients subsequently died, nine of them from cardiovascular disease. Nine patients developed symptoms of angina de novo during CAPD. Seven patients had a history of stroke when they started CAPD, but none died or had a further stroke during follow up. Six fatal and two non-fatal strokes occurred in the rest of the population who received CAPD.

Peritonitis-Five hundred and fifty five episodes of peritonitis, at a mean rate of one episode per 35 patient weeks, were recorded during the five years. The rate varied around the mean from year to year but showed no consistent trend towards improving on the first year's rate. Three hundred and ninety four episodes of infection $(71 \%)$ were successfully cleared by one course of antibiotics. In 116 episodes $(21 \%)$ the infection recurred after a course of antibiotics and was successfully cleared by a further course of treatment in 92 , giving an overall successful outcome in 486 episodes (88\%). In seven patients peritonitis led to obliteration of the peritoneal space, making it impossible to reinsert the catheter. The most common organism causing peritonitis was Staphylococcus epidermidis, which was isolated in 206 episodes (37\%). Gram positive organisms were isolated in 288 episodes (52\%), Gram negative in $91(16 \%)$, and yeasts in $10(2 \%)$, and no growth occurred in 166 episodes (30\%)

Abdominal complications-Eight of the 46 deaths (17\%) of patients treated with CAPD were due to abdominal complications, compared with two of 50 (4\%) who had never been treated with CAPD. Seventeen patients underwent laparotomy for acute abdominal problems. Three of these patients had an intra-abdominal abscess, and six required bowel resection. Pseudomembranous colitis developed in 16 patients during an outbreak in $1982,{ }^{10}$ but there were no subsequent episodes. Thirty two patients had 41 hernias repaired, nine of which were repaired before starting CAPD.

Peritoneal function-Peritoneal clearance was inadequate in two patients who were transferred to haemodialysis after a trial of CAPD. Progressive loss of ultrafiltration was noted in four patients who had had multiple episodes of peritonitis. Mean plasma creatinine concentrations increased slowly after six

TABLE III-Reasons for permanent or temporary interruption of treatment in patients undergoing treatment with continuous ambulatory peritoneal dialysis

\begin{tabular}{lc}
\hline \multicolumn{1}{c}{ Reason for stopping treatment } & No of patients \\
\hline \multicolumn{1}{c}{ Permanent } \\
Peritonitis & 44 \\
Transplant & 38 \\
Died & 15 \\
Inadequate dialysis & 6 \\
Unable to manage the technique & 8 \\
Abdominal complications & 5 \\
Other & 11 \\
\hline Total & 127 \\
\hline & \\
Peritonitis & \\
Hernia & 25 \\
Other abdominal problem & 7 \\
Catheter problem & 8 \\
Fluid leak & 6 \\
Transplant months) & 5 \\
Return of function & 12 \\
Other & 2 \\
Total & 3 \\
\hline
\end{tabular}

TABLE IV-Mean (SEM) creatinine and urea concentrations and No of hypertonic exchanges/day in patients before and during treatment with continuous ambulatory peritoneal dialysis (CAPD)

\begin{tabular}{ccccc}
\hline $\begin{array}{c}\text { Length of } \\
\text { treatment } \\
\text { with CAPD } \\
\text { (months) }\end{array}$ & $\begin{array}{c}\text { Creatinine } \\
(\mu \mathrm{mol} / \mathrm{l})\end{array}$ & $\begin{array}{c}\text { Urea } \\
(\mathrm{mmol} / \mathrm{l})\end{array}$ & $\begin{array}{c}\text { No of } \\
\text { hypertonic exchanges/ } \\
\text { day }\end{array}$ & $\mathrm{n}$ \\
\hline 0 & $1195(25)$ & $38 \cdot 1(1 \cdot 1)$ & & 222 \\
6 & $961(20)$ & $21 \cdot 1(0.5)$ & $0 \cdot 71(0.05)$ & 200 \\
12 & $1027(22)$ & $21 \cdot 1(0.5)$ & $0 \cdot 80(0.06)$ & 156 \\
24 & $1099(33)$ & $22 \cdot 2(0.6)$ & $0 \cdot 84(0.08)$ & 83 \\
36 & $1100(46)$ & $22 \cdot 1(1 \cdot 3)$ & $0.81(0.05)$ & 33 \\
48 & $1170(80)$ & $22 \cdot 7(2 \cdot 0)$ & $0.82(0.08)$ & 11 \\
\hline
\end{tabular}

Conversion : SI to traditional units -Creatinine: $1 \mu \mathrm{mol} / \mathrm{l} \approx 0.01 \mathrm{mg} / 100 \mathrm{ml}$. Urea: $1 \mathrm{mmol}$ $\mathrm{l} \approx 6 \mathrm{mg} / 100 \mathrm{ml}$. months of receiving CAPD, whereas mean urea concentrations and the number of hypertonic exchanges a day were unchanged (table IV).

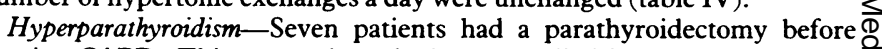
starting CAPD. Thirteen patients had uncontrolled hyperparathyroidisme during treatment and required parathyroidectomy. Of these, eight patients had previously received transplants or haemodialysis for over 12 months and had moderate or severe hyperparathyroidism at the start of CAPD. Only five patients had been treated solely with CAPD. A further four patients $\mathbb{D}$ developed progressive hyperparathyroidism after stopping CAPD and transferring to haemodialysis; they underwent parathyroidectomy.

Other complications - The catheter was removed or replaced because of poor flow (11 patients), malposition (nine), exit tract infection (four), and fluid leak or damaged catheter (four). Three patients underwent bilateral nephrectomy for uncontrolled hypertension.

Admissions to hospital-Half of all the days spent in hospital by patients $\frac{\bar{\sigma}}{\overline{0}}$ were caused by peritonitis (table V). The mean number of days spent in $\frac{\bar{T}}{\partial}$

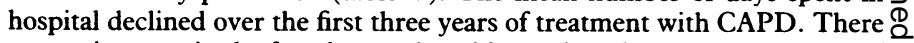
was an increase in the fourth year, but this was based on a small number of patients.

TABLE V-Time spent in hospital by patients being treated with continuous ambulatory peritoneal dialysis (CAPD)

\begin{tabular}{cccr}
\hline \multirow{2}{*}{$\begin{array}{c}\text { Period after starting } \\
\text { CAPD (months) }\end{array}$} & \multicolumn{3}{c}{ Mean No of days/patient } \\
\cline { 2 - 4 } & Peritonitis & Other & Total \\
\hline 0 to 6 & $5 \cdot 3$ & $4 \cdot 3$ & $19 \cdot 0$ \\
6 to 12 & $4 \cdot 2$ & $5 \cdot 2$ & 12 \\
12 to 24 & $5 \cdot 2$ & $7 \cdot 1$ & $12 \cdot 3$ \\
24 to 36 & $3 \cdot 9$ & $3 \cdot 9$ & $7 \cdot 9$ \\
36 to 48 & $7 \cdot 9$ & $5 \cdot 7$ & $13 \cdot 6$ \\
\hline
\end{tabular}

\section{Discussion}

The increased use of CAPD has had an appreciable effect on the treatment of chronic renal failure in Newcastle. In the early years it $\vec{\emptyset}$ allowed an expansion in the number of patients treated without an increase in facilities for haemodialysis. Some patients received successful transplants after receiving CAPD. ${ }^{12}$ This period, however, has ended, and more facilities for haemodialysis are now needed if the number of transplants performed annually does not increase.

We have previously reported actuarial survival of patients receiving CAPD as being $94 \%$ at two years. ${ }^{7}$ That excellent result $\frac{0}{3}$ encouraged us to continue and expand our programme of CAPD, $\frac{3}{\overrightarrow{3}}$ and it is therefore disappointing to see that this survival curve has not been maintained. There are several possible explanations. Firstly, in our previous reports we have counted as a death while receiving CAPD only those events that occurred while the patient was receiving that treatment or during an acute illness that began $\frac{0}{3}$ while CAPD was in progress. This gives an over optimistic picture of the procedure, as patients who are not doing well while receiving CAPD are transferred to haemodialysis, to which their subsequent deaths are attributed. Some authors have counted deaths during an 윽 arbitrary period-for example, three months-after a change of $N$ treatment as attributable to the first treatment. In this study we have analysed our data on the "intention to treat" principle. Patients who started CAPD were followed to the end of the study (December 1984 or earlier death), and all deaths were counted, whether they $\mathrm{N}_{\mathrm{W}}$
occurred during CAPD or subsequent treatments.

Secondly, it is an observed, though largely unexplained, fact 2 that actuarial survival curves give an over optimistic forecast of $\stackrel{0}{\varnothing}$ eventual survival (Bradley BA, personal communication). As data accumulates the actuarial survival curve is increasingly based on patients who have passed the final point, so results usually $\frac{0}{0}$ deteriorate.

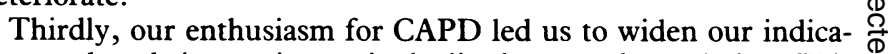

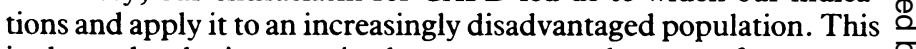
is shown by the increase in the mean age at the start of treatment during the study.

Despite this deterioration in our survival curve the results are similar to the European average survival for non-diabetic patients who started renal replacement treatment over the same period. At $\stackrel{?}{\rightleftharpoons}$ 
36 months this varied from $84 \%$ for those aged $15-34$ to $47 \%$ for those aged 65 years and over. ${ }^{4}$ They are better than the overall results from Europe in the same report. The Toronto group has continued to report an actuarial survival of $82 \%$ at two years, ${ }^{13}{ }^{14}$ and the United States registry reports a cumulative probability of dying while receiving CAPD of $26 \%$ at two years in 7404 patients. ${ }^{15}$ These results cannot rival the best results of haemodialysis reported from a few centres with an actuarial survival of over $90 \%$ at two years ${ }^{16}$ but they are similar to those expected from conventional haemodialysis schedules. ${ }^{417}$

Cardiovascular disease remains the main cause of death in all reported groups of dialysis patients. On this evidence CAPD does not seem to exert a particularly detrimental effect on cardiovascular mortality or morbidity. Patients with pre-existing ischaemic heart disease do, however, have a worse outlook than those without, as expected. More worrying is the high incidence of death from abdominal complications, which, in most cases, are directly related to treatment with CAPD. The European registry has also suggested that abdominal causes of death, including complications not directly related to peritonitis such as perforated peptic ulcer, are increased in patients receiving CAPD. The incidence of deaths related to peritonitis has been much higher in other reports, however, ${ }^{18}{ }^{19}$ and we have not seen lethal sclerosing peritonitis.

Efforts to reduce the mortality of patients receiving CAPD should therefore concentrate on the prevention of infection and early diagnosis of intra-abdominal catastrophe. Bazzato et al have reported excellent results in the prevention of infection with a double bag system, ${ }^{20}$ and many other systems are under trial. It seems sensible to remove infected catheters more readily. Our current policy is to remove the catheter if the infection has not responded to five days' treatment with an appropriate antibiotic, or if the infection recurs despite two courses of antibiotics. The infecting organism should also be taken into account. A fungal infection is rarely cured by antibiotics and is an indication for early removal. A Gram negative infection should alert the clinician to the possibility of bowel perforation.

This study emphasises the need for extensive back up haemodialysis and surgical facilities when running a programme of CAPD. Many patients require a temporary period on haemodialysis, and $35 \%$ to $45 \%$ of patients change their mode of treatment or die within two years of starting CAPD. Despite treating half of the episodes of peritonitis at home inpatient beds are required for one to two weeks per patient year.

There is no absolute bar to long term treatment with CAPD; indeed, one of our patients has now been treated this way for more than six years. In our patients the incidence of failure of the peritoneal membrane has been low, and we have not seen sclerosing peritonitis in the absence of severe infection. The main limiting factor was peritonitis. The tendency of serum creatinine concentration to increase with increasing length of treatment with CAPD suggests that peritoneal function may decline slowly or that muscle mass increases with increased length of treatment with CAPD, though residual renal function presumably also declines and was not routinely measured in our patients. A cross sectional analysis of peritoneal function by a single hypertonic exchange in our patients suggested a decline in peritoneal clearance with time, predicting a $50 \%$ loss of function after an average of 13 years of being treated with CAPD. ${ }^{21}$ Although this observation needs to be confirmed by careful assessment over several years of peritoneal function in many patients receiving CAPD, it suggests that loss of clearance is unlikely to be a problem in most patients awaiting a transplant. There is no evidence to suggest sequential loss of ultra-filtration during treatment with CAPD in our patients, though this has been recognised in other centres. ${ }^{22}$ The true potential of the peritoneum will only be clear when effective methods of preventing infection have been developed.

We have previously reported that CAPD provides good control of seconaary hyperparathyroidism. ${ }^{8}$ While this remains generally true it seems that CAPD cannot always reverse or hold established hyperparathyroidism in patients who have been treated for some time with some other mode of treatment.

What, then, is the present role of CAPD? Its use in children ${ }^{23}$ or elderly $^{24}$ or diabetic patients ${ }^{25}$ is not controversial, and our data suggest that it is also a reasonable option for young, fit patients if it is used as a medium term measure before a transplant. ${ }^{12}$ The increased use of CAPD has partly been related to its advantages over haemodialysis, particularly the general impression, now backed up by some studies, that the quality of life of patients receiving CAPD is better than that of those receiving haemodialysis. ${ }^{2627}$ The short training period for CAPD compared with that required for home haemodialysis also makes it possible to accept more patients for treatment. These benefits must be weighed against the evidence that survival of patients receiving CAPD may be reduced compared with that in those receiving haemodialysis. Young patients unsuitable for receiving a transplant should be offered haemodialysis if it is available. Many units will continue to prefer haemodialysis as the safer option for most young patients, who for any reason must expect a long wait before receiving a transplant. If the average success in preventing peritonitis can be brought up to the best standards that have been reported, however, CAPD may be a reasonable long term treatment.

We thank all medical, surgical, and nursing colleagues who helped to look after the patients, as well as the dietetic and laboratory staff and all others who helped the programme to run. We are particularly grateful to Carole Shipley for organising the notes and to Christine Harvey for typing the manuscript.

\section{References}

1 Popovich RP, Moncrief JW, Decherd JF, Bomar JB, Pyle WK. The definition of a novel portablewearable equilibrium peritoneal dialysis technique. Abstracts of the American Society for Artificial Internal Organs 1976;5:64.

2 Oreopoulos DG, Robson M, Faller B, Ogilvie R, Rapoport A, de Veber GA. Continuous ambulatory peritoneal dialysis: a new era in the treatment of chronic renal failure. Clin Nephrol 1979;11:125-8.

3 Kramer P, Broyer M, Brunner FP, et al. Combined report on regular dialysis and transplantation in Europe, XIV, 1983. Proc Eur Dial Transplant Assoc 1984;21:5-65.

4 Wing AJ, Broyer M, Brunner FP, et al. Combined report on regular dialysis and transplantation in Europe, XIII, 1982. Proc Eur Dial Transplant Assoc 1983;20:5-75.

5 Fragola JA, Grube S, Von Bloch L, Bourke E. Multicentre study of physical activity and employment status of continuous ambulatory peritoneal dialysis (CAPD) patients in the United States. Proc Eur Dial Transplant Assoc 1983;20:243-9.

6 DePaepe $M$, Schelstraete $K$, Ringoir $S$, Lameire $N$. Influence of continuous ambulatory peritoneal dialysis on the anaemia of end-stage renal disease. Kidney Int 1983;23:744-8.

7 Ramos JM, Gokal R, Siamopolous K, Ward MK, Wilkinson R, Kerr DNS. Continuous ambulatory peritoneal dialysis: three years' experience. $Q \mathcal{F}$ Med 1983;52:165-86.

8 Cassidy MJ, Owen JP, Ellis HA, et al. Renal osteodystrophy and metastatic calcification in longterm continuous ambulatory peritoneal dialysis. Qf Med 1985;54:29-48.

9 Gokal R, McHugh M, Fryer R, Ward MK, Kerr DNS. Continuous ambulatory peritoneal dialysis: one year's experience in a UK dialysis unit. BrMed $\mathcal{F} 1980 ; 281: 474-7$.

10 Gokal R, Ramos JM, Francis DMA, et al. Peritonitis in continuous ambulatory peritoneal dialysis. Laboratory and clinical studies. Lancet 1982;ii:1388-91.

11 Barnes BA. Survival data for renal patients. Transplantation 1965;3:812-21.

12 Donnelly PK, Lennard TWJ, Proud G, et al. Continuous ambulatory peritoneal dialysis and renal transplantation: a five year experience. $\mathrm{Br} \mathrm{Med} \mathcal{F}$ 1985;291:1001-4.

13 Khanna R, Oreopoulos DG, Dombros N, et al. Continuous ambulatory peritoneal dialysis (CAPD); after three years still a promising treatment. Peritoneal Dialysis Bulletin 1981;1:24-34.

14 Khanna R, Wu G, Vas S, Oreopoulos DG. Mortality and morbidity on continuous ambulatory peritoneal dialysis. American Society of Artificial Internal Organs Journal 1983;6:197-204.

15 Nolph KD, Cutler JS, Steinberg SM, Novak JW. Continuous ambulatory peritoneal dialysis in the United States: a three year study. Kidney Int 1985;28:198-205.

16 Laurent G, Calemard E, Charra B. Long dialysis: a review of fifteen years' experience in one centre 1968-1983. Proc Eur Dial Transplant Assoc 1983;20:122-35.

17 Lloyd C, Baillod R, Gokal R, et al. Multi centre study on outcome of patients on CAPD and haemodialysis (HD). Peritoneal Dialysis Bulletin 1984;4(suppl):37S.

18 Slingeneyer A, Mion C, Beraud JJ, Oules R, Branger B, Balmes M. Peritonitis, a frequently lethal complication of intermittent and continuous ambulatory peritoneal dialysis. Proc Eur Dial Transplant Assoc 1981;18:212-21.

19 Fenton SSA and The University of Toronto Collaborative Dialysis Group. Peritonitis-related deaths among CAPD patients. Peritoneal Dialysis Bulletin 1983:3(suppl):9-11S

20 Bazzato G, Coli U, Landini S, et al. The double bag system for CAPD reduces the peritonitis rate. Trans Am Soc Artif Intern Organs 1984;30:690-2.

21 Nikolakakis N, Rodger RSC, Goodship THJ, et al. The assessment of peritoneal function using single hypertonic exchange. Peritoneal Dialysis Bulletin 1985;5:186-8.

22 Nolph KD. An international co-operative study-second report, 29 participating centres. A survey of ultrafiltration in continuous ambulatory peritoneal dialysis. Peritoneal Dialysis Bulletin 1984;4:137-42.

23 Baum M, Powell D, Calvin S, et al. Continuous ambulatory peritoneal dialysis in children Comparison with haemodialysis. N Engl f Med 1982;307:1537-42.

24 Nicholls AJ, Waldek S, Platts MM, Moorhead PJ, Brown CB. Impact of continuous ambulatory peritoneal dialysis on treatment of renal failure in patients aged over $60 . \mathrm{Br} M e d \mathcal{F} 1984 ; 288$ : $18-9$.

25 Flynn CT. Long-term continuous ambulatory peritoneal dialysis. Proc Eur Dial Transplant Assoc 1983;20:700-4.

26 Simmons RG, Anderson C, Kamstra L. Comparison of quality of life of patients on continuous ambulatory peritoneal dialysis, hemodialysis and transplantation. Am $\mathcal{f}$ Kidney Dis 1984;3: $253-5$.

27 Evans RW, Manninen DL, Garrison LP, Jr, et al. The quality of life of patients with end-stage renal disease. $N$ Engl f Med 1985;312:553-9.

(Accepted 28 fuly 1986) 